\title{
Akutt inneklemming av tarm etter gastrisk bypass for sykelig fedme
}

\author{
BAKGRUNN Det utføres rundt 3000 fedmeoperasjoner i Norge hvert år. Laparoskopisk \\ gastrisk bypass er den mest brukte metoden. Inneklemming av tarm er en potensielt alvor- \\ lig årsak til akutte magesmerter etter gastrisk bypass.
}

KUNNSKAPSGRUNNLAG Oversiktsartikkelen baseres på et skjønnsmessig utvalg av artikler funnet i PubMed samt forfatternes egne kliniske erfaringer.

RESULTATER Inneklemming av tarm gjennom defekter eller drag i tarmkrøset etter gastrisk bypass, ofte kalt mesenteriale slitser, forekommer hos anslagsvis $0-10 \%$ av pasientene. Forekomsten avhenger av bl.a. oppfølgingstid, kirurgisk teknikk og om de mesenteriale slitsene ble lukket ved operasjonen. Smertene kan være akutte, intense og vedvarende med kvalme og oppkast, eller intermitterende etter matinntak. Ved akutt smerte kan det foreligge obstruksjon og redusert blodsirkulasjon til tarm med behov for øyeblikkelig operativ behandling. CT-undersøkelse kan påvise eller gi mistanke om, men ikke utelukke, obstruksjon. Graviditet er en risikofaktor, og kvinner i fertil alder bør spesielt opplyses om dette. Mange anbefaler lukning av mesenteriale slitser ved primæroperasjonen for å redusere risiko for inneklemming.

FORTOLKNING Inneklemming av tarm etter gastrisk bypass er en potensielt alvorlig og ikke uvanlig komplikasjon som kan kreve rask operativ intervensjon. Alle avdelinger med akutt abdominalkirurgisk beredskap bør kjenne tilstanden.

Omkring 3000 pasienter opereres for sykelig fedme i Norge hvert år. I tillegg opereres et ukjent antall nordmenn i utlandet. Laparoskopisk gastrisk bypass er den vanligste operasjonsmetoden $(1,2)$. Andre metoder er båndoperasjoner, langsgående ventrikkelstapling (sleeve) og biliopankreatisk avledning med duodenal omkobling.

Magesmerter etter gastrisk bypass kan ha flere årsaker, og diagnostikken kan være vanskelig. En ikke uvanlig årsak til akutte smerter er en ileustilstand med inneklemming av tarm pga. endret intraabdominal anatomi etter operasjonen. Forløpet hos disse pasientene kan være dramatisk og medføre nekrose av deler av tarm. Tilstanden krever rask utredning og behandling.

Hensikten med denne artikkelen er å gi helsepersonell som håndterer akutte abdominaltilstander oppdatert informasjon om denne potensielt livstruende komplikasjonen etter gastrisk bypass.

\section{Materiale og metode}

Oversiktsartikkelen er basert på et skjønnsmessig utvalg av engelskspråklige originalartikler og oversiktsartikler funnet i PubMed med bruk av søkekombinasjoner som «gastric bypass and internal herniation», «bariatric surgery and internal herniation» frem til og med september 2012. Vi har også med egne erfaringer med pasientgruppen ved Senter for sykelig overvekt i Helse Sør-Øst og Gastrokirurgisk avdeling, Oslo universitetssykehus.

\section{Definisjon}

Intern herniering defineres som inneklemming av vanligvis tynntarm gjennom mesenteriale defekter eller drag som oppstår $i$ det man kobler om tynntarm til en Roux-enY-konfigurasjon som del av gastrisk bypass (fig 1, fig 2). Disse mesenteriale defektene eller dragene som gir mulighet for inneklemming av tarm, kalles ofte mesenteriale slitser. En slik herniering kan være spontant irreversibel eller intermitterende. Ved intermitterende herniering kan tarmen skli ut og inn av slitsene uten strangulasjon, men kan likevel medføre plager for pasienten. Ved irreversibel herniering er tarmen inneklemt og fastsittende, noe som kan medføre ileus og kompromittert blodsirkulasjon.

Intern herniering forekommer også etter andre inngrep som biliopankreatisk avledning med duodenal omkobling og gastrektomi med Roux-en-Y-løsning (3). Den kan også forekomme spontant hos pasienter uten tidligere abdominal kirurgi. To tilfeller av intern herniering gjennom foramen Winslowi til bursa omentalis ble beskrevet i Tidsskriftet for over 30 år siden (4).

\section{Forekomst}

Forekomsten av intern herniering etter laparoskopisk gastrisk bypass varierer betydelig i ulike pasientserier, fra $0 \%$ til $10 \%$ (tab 1 ) (5-14). I en studie med lang oppfølgingstid, men med lav oppmøteprosent blant pasientene, forekom intern herniering hos $16 \%$ (15). I denne studien hadde man benyttet

\section{Tom Mala}

tom.mala@ous-hf.no

Jon Kristinsson

Avdeling for gastro- og barnekirurgi

og

Senter for sykelig overvekt i Helse Sør-Øst Oslo universitetssykehus

Se også kunnskapsprøve på www.tidsskriftet.no/quiz

\section{HOVEDBUDSKAP}

Akutt abdomen etter gastrisk bypass kan skyldes inneklemming av tarm gjennom defekter i mesenteriet

Akutt inneklemming kan føre til ileus og nekrose av tarm

Anamnese sammen med kliniske funn er viktigste redskap i diagnostikken

Laparoskopi eller laparotomi bør alltid vurderes ved uklare magesmerter etter gastrisk bypass 
retrokolisk plassering av tarmløpet opp mot gastrojejunostomien. Den reelle forekomsten er vanskelig å vite sikkert og avhenger av bl.a. operasjonstype, oppfølgingskvalitet, observasjonstid og oppmøteprosent.

Hvordan man definerer intern herniering kan også være av betydning for angivelse av forekomst. Enkelte pasienter opereres pga. symptomer, kliniske og/eller radiologiske funn som gir sterk mistanke om intern herniering. Under operasjonen kan tarmen være spontanreponert, og man vil da ikke påvise manifest herniering, men åpne slitser uten andre årsaker til pasientens plager. Plagene kan da forsvinne etter at slitsene er lukket. Dette kan være uttrykk for intermitterende herniering. Om disse pasientene anses å ha intern herniering eller ikke, er ikke alltid spesifisert.

I en studie med gjennomsnittlig ni års oppfølging utviklet $9,3 \%$ av pasientene intern herniering (14). I en annen analyse av 2472 pasienter estimerte man femårsrisikoen for intern herniering til å være rundt $11 \%$ (13). I en oversiktsartikkel basert på 26 studier der oppfølgingstiden var klart angitt $\mathrm{i}$ bare fem studier, var forekomsten av intern herniering $2,5 \%$ (16). Metodologiske svakheter og forskjeller ved de ulike studiene vanskeliggjør tolkingen. Både pasienter med retrokolisk og antekolisk lokalisasjon av det alimentære løpet var inkludert, og bare få av studiene anga lengden på oppfølgingen etter gastrisk bypass eller når i forløpet intern herniering tilkom. I tillegg var pasienter både med og uten primær lukning av slitsene inkludert.

\section{Etiologi}

I Norge benyttes vanligvis antekolisk plassering av tarmløpet som løftes opp mot magesekken (fig 1). Dermed forekommer intern herniering $\mathrm{i}$ utgangspunktet ved to lokalisasjoner - ved enteroenteroanastomosen eller bak tarmløpet som er løftet opp mot magesekken (Petersens rom) (fig 2a, fig $2 b$ ). Ved enkelte sykehus benyttes retrokolisk plassering av tarmløpet opp mot magesekken. Da kan tarmen også herniere gjennom slitsen i mesocolon (15).

Mange hevder at risikoen for herniering øker etter vekttap fordi de mesenteriale slitsene blir større når mengden intraabdominalt fett reduseres. Noen angir også at pasienter med spesielt raskt vekttap er mer utsatt (17). Hvordan man legger de ulike tarmløpene og lengden på løpene ved primæroperasjonen kan ha betydning for hyppigheten $(18,19)$. Mindre plass i buken og endret anatomi ved graviditet kan også være

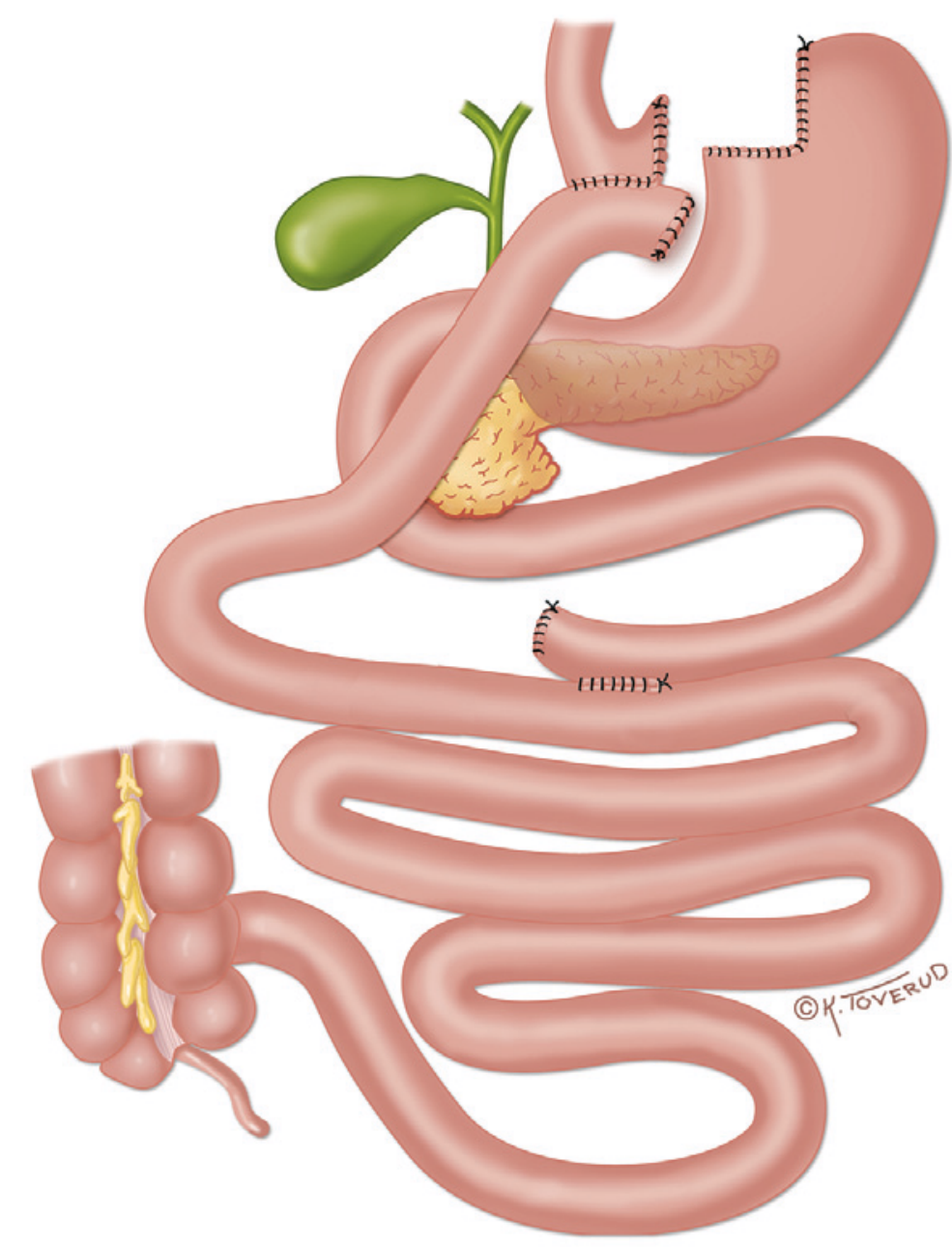

Figur 1 Gastrisk bypass. I Norge anlegges rutinemessig det alimentære løpet antekolisk (foran colon). Man slipper da å lage åpning i colonkrøset for å løfte løpet opp bak colon. Det gir en mindre åpning der tarmen kan herniere. Tidligere publisert i Hofsø og medarbeidere (1)

en risikofaktor for utvikling av intern herniering og kan muligens lettere medføre strangulasjon av tarm (20).

Forekomsten av intern herniering etter gastrisk bypass utført ved laparotomi synes å være lavere enn etter laparoskopisk tilgang. Dette skyldes trolig mindre intraabdominal adheransedanning etter laparoskopi (16). Åpen tilgang benyttes nå imidlertid sjelden.

\section{Symptomer og kliniske funn}

Intern herniering kan i prinsippet oppstå når som helst etter gastrisk bypass. I en belgisk studie utviklet $9,3 \%$ av pasientene intern herniering etter median 4,8 år (spredning 1-9 år) etter gastrisk bypass (14). I en annen studie utviklet 117 pasienter $(4,7 \%)$ intern herniering etter gjennomsnittlig 13 måneder (spredning 4-43 måneder) (13). Dette kan tolkes som at mange av pasientene utvikler intern herniering relativt tidlig, men at tilstanden også kan tilkomme mange år etter gastrisk bypass.

De vanligste symptomene ved intern herniering er buksmerter, som kan være lokalisert mot venstre hypokondrium. Noen pasienter angir stråling mot rygg. Ved akutt inneklemming kan pasienten være betydelig smertepåvirket. Ved intermitterende herniering kan pasientene beskrive plager som kommer og går, og som gjerne provoseres av matinntak, men som slipper etter en stund. Brekninger og kvalme kan følge med (5). Ved undersøkelsen er pasienten smertepåvirket og abdomen øm ved palpasjon. I noen tilfeller kan man palpere en resistens $\mathrm{i}$ 

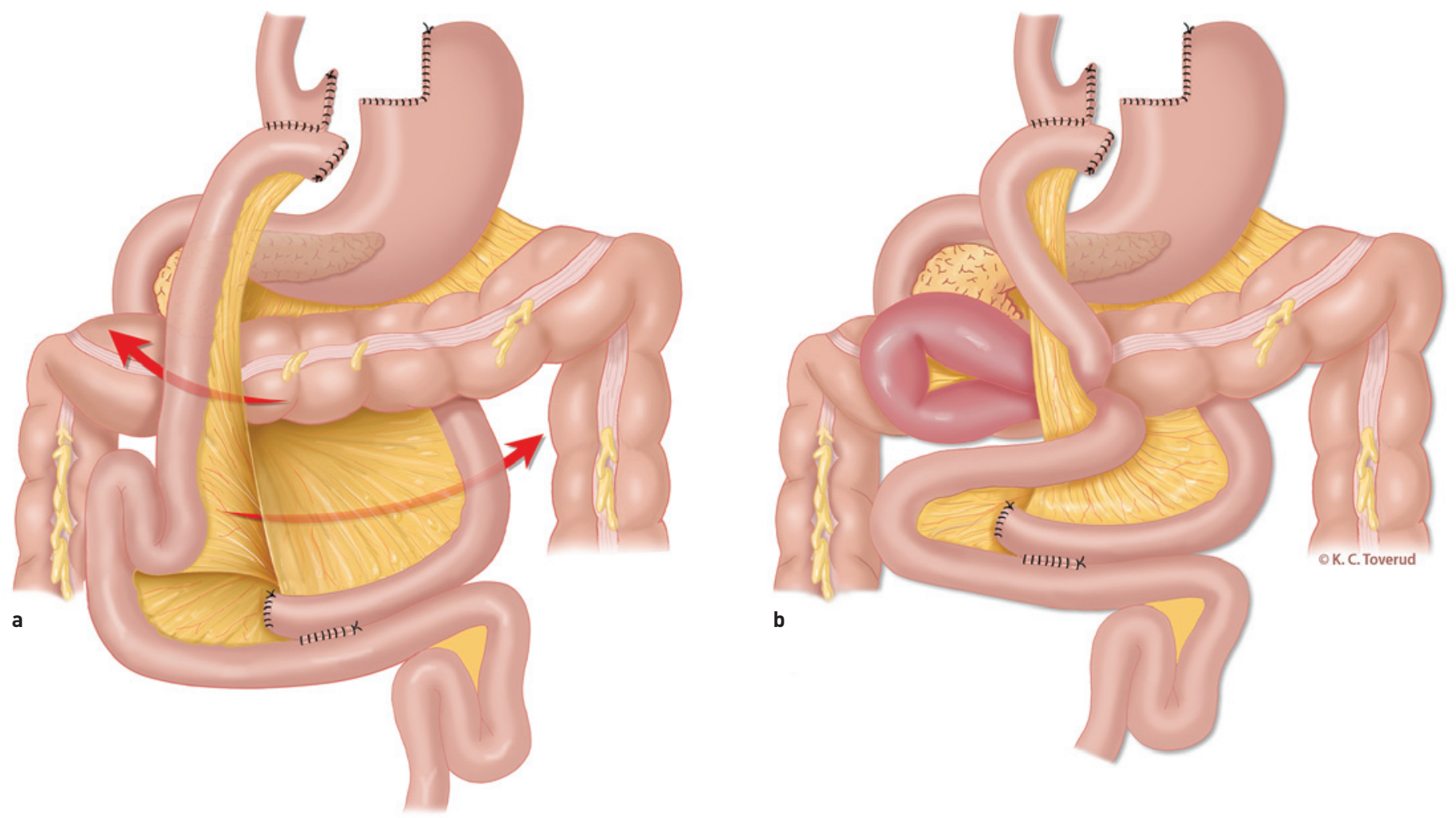

Figur 2 Herniering av tarm. al Typiske lokalisasjoner for herniering etter antekolisk gastrisk bypass. Den øvre pilen viser herniering gjennom Petersens rom, den nedre ved enteroenteroanastomosen. b) Eksempel på en variant av herniering gjennom Petersens rom ved antekolisk lokalisasjon av det alimentære løpet. Tarmen roterer rundt seg selv og hernierer bak mesenteriet til det alimentære løpet som er løftet opp mot magesekken foran colon

buken. Kliniske funn vil avhenge av obstruksjonsgrad og om sirkulasjonen til tarmen er truet, noe som etter hvert vil kunne føre til mer alvorlige symptomer.

Magesmerter som uttrykk for intern herniering etter gastrisk bypass hos gravide er beskrevet av flere $(21,22)$. Hos slike pasienter er det viktig å ha lav terskel for laparoskopi med reponering av herniert tarm og eventuelt keisersnitt for å redusere risiko for alvorlige konsekvenser for mor og foster (20).

\section{Diagnostikk}

Viktigste redskap i diagnostikken er klinisk mistanke og kjennskap til tilstanden. Blodprøvene er ofte av liten verdi i tidlig fase og dersom det ikke foreligger akutt sirkulasjonspåvirket tarm. Anamnese med inter- mitterende, gjerne øvre magesmerter som utløses kort tid etter matinntak bør gi mistanke om intern herniering.

Et vanlig røntgenoversiktsbilde gir lite diagnostisk informasjon, men kan påvise dilatert tarm med væskespeil som ved ileus. Computertomografi (CT) av abdomen med peroral og intravenøs kontrast kan vise såkalt virveltegn (swirl sign), som indikerer rotasjon av tynn-

Tabell 1 Forekomst av intern herniering av tarm etter laparoskopisk antekolisk gastrisk bypass i ulike studier

\begin{tabular}{|c|c|c|c|c|c|c|}
\hline Førsteforfatter & $\AA ̊ 丿$ & $\begin{array}{l}\text { Antall } \\
\text { pasienter }\end{array}$ & Andel (\%) fulgt opp & Oppfølgingstid & Forekomst (\%) & Kommentar \\
\hline Comeau (5) & 2005 & 731 & Ikke spesifisert & Ikke angitt & 3,3 & Slits lukket hos noen pasienter \\
\hline Cho (6) & 2006 & 1400 & 59 (etter ett år) & $11 \mathrm{md}(0,4-48 \mathrm{md})^{1}$ & 0,2 & Slits ikke lukket primært \\
\hline lannelli (7) & 2007 & 625 & Ikke spesifisert & Ikke angitt & 1,6 & Slits lukket hos de siste 155 pasientene \\
\hline Steele (8) & 2008 & 205 & Ikke spesifisert & Minst $18 \mathrm{md}$ & 0 & Slits lukket primært \\
\hline Gandhi (9) & 2009 & 702 & 75 (etter ett år) & Ikke angitt & 2,1 & $\begin{array}{l}\text { Hel eller delvis lukking av slits } \\
\text { ved enteroenteroanastomosen }\end{array}$ \\
\hline Bauman (10) & 2009 & 1047 & Ikke spesifisert & Ikke angitt & 6,9 & Slits ikke lukket primært \\
\hline Rodriquez (11) & 2010 & 359 & Ikke spesifisert & $<36 \mathrm{md}^{1}$ & 8,1 & $\begin{array}{l}\text { Slits lukket bortsett fra ved Petersens } \\
\text { rom (187 pasienter) }\end{array}$ \\
\hline Abasbassi (12) & 2011 & 652 & Ikke spesifisert & $45 \mathrm{md}^{1}$ & 6,9 & Slits ikke lukket primært \\
\hline Aghajani (13) & 2012 & 2472 & Ikke spesifisert & $23 \mathrm{md}(7-64 m d)^{2}$ & 4,7 & Slits ikke lukket primært \\
\hline Himpens (14) & 2012 & 77 & 61,1 & 9,4 år $(8,7-10,9 \text { år })^{1}$ & 9,3 & Slits lukket primært \\
\hline
\end{tabular}

${ }^{1}$ Gjennomsnitt (spredning)

${ }^{2}$ Median (spredning) 
tarmskrøset med torsjon av krøskar (23). Mistanken kan styrkes av struttende kar/lymfe i krøset og at mye av tarmen ligger til venstre $i$ buken. Det kan foreligge fri væske i buken. Det er også beskrevet andre radiologiske karakteristika (23). Tilstanden kan imidlertid ikke utelukkes ved CT-undersøkelse. Ved sterk klinisk mistanke bør man da vurdere diagnostisk laparoskopi, eventuelt laparotomi.

Symptombilde er avgjørende for om man bør gjøre relaparoskopi på en pasient som tidligere har fått lukket slitsene. Lukning av slitsene betyr ikke nødvendigvis at slitsene er lukket på det tidspunktet pasienten har akutte smerter.

\section{Behandling}

Behandling ved akutt inneklemming etter gastrisk bypass er operasjon, enten laparoskopi eller laparotomi. Man prøver under operasjonen å få oversikt over de ulike tarmløpene (fig 1) og undersøker om tarmen ligger som den skal i forhold til enteroenteroanastomosen og de øvrige tarmløpene. Etter vår erfaring forekommer intern herniering hyppigst ved enteroenteroanastomosen, men ulike studier angir ulik hyppighet av herniering ved de potensielle lokalisasjonene (16). Ved herniering reponeres tarmen og slitsene lukkes ved henholdsvis enteroenteroanastomosen og ved Petersens rom (fig 2). Det er flere måter å lukke slitsene på etter at tarmen er reponert. I akutte situasjoner har vi foretrukket å bruke sutur.

Typiske peroperative funn ved akutt inneklemming er dilatert, sirkulasjonstruet og misfarget tarm. Tarmreseksjon må da vurderes. Ødematøse forandringer i krøset, fri væske i buken og struttende lymfekar i tarmveggen kan også forekomme som uttrykk for inneklemming. Rask diagnostikk og intervensjon reduserer risikoen for tarmreseksjon og dermed risiko for kort tarm-syndrom.

Intern herniering etter gastrisk bypass kan vanligvis håndteres laparoskopisk, men det kan være vanskelig å få oversikt over alle tarmløp (16). Enkelte ganger er tarmen så fastsittende at tynntarmskader tilkommer når man prøver å få tarmen løs. Man må da konvertere til laparotomi for å få bedre oversikt og for å håndtere tarmen mer skånsomt. Kirurgisk snitt på dilatert tarm med evakuering av tarminnhold kan være nødvendig for å få til reponering. Enkleste måte å skaffe seg oversikt og å få reponert tarmen på er vanligvis å begynne ved ileocøkalstedet og bla seg opp mot enteroenteroanastomosen. Deretter finner man biliopankreatisk løp og blar fra enteroenteroanastomosen opp til treitzske ligament. Til slutt finner man gastrojejunostomien og blar ned til enteroenteroanastomosen. Hvis dette gjøres riktig, ligger tarmen riktig og slitsene kan lukkes.

\section{Profylaktisk lukning av mesenteriale slitser}

Mange anbefaler lukning av slitsene ved primæroperasjonen som profylakse mot senere utvikling av intern herniering $(8,10,11)$. Noen hevder imidlertid at lukning av slitsene kan føre til komplikasjoner som blødning og knekkdanning på tarmen med subileus/ileus som resultat, men dette er så langt ikke godt dokumentert.

Hvordan slitsene bør lukkes, er også omdiskutert. Mange benytter sutur, men det er også utviklet en teknikk der med stapler (13). I en pasientserie utviklet $9,3 \%$ av pasientene intern herniering på tross av at slitsene var lukket både ved enteroenteroanastomosen og Petersens rom med ikke-resorberbar sutur. Dette mente man skyldtes at trådene som var benyttet til å lukke slitsene, hadde skåret gjennom vevet og at defektene da ble reetablert (14). En annen studie viste at hos 15 av 18 pasienter som ble reoperert etter tidligere gastrisk bypass, var slitsen ved enteroenteroanastomosen åpen selv etter tidligere lukning (24). I Norge lukkes vanligvis slitsene, men også etter vår erfaring kan intern herniering oppstå hos pasienter som tidligere har fått lukket slitsene.

\section{Diskusjon}

Akutte magesmerter etter gastrisk bypass kan ha mange årsaker som ikke er direkte relatert til gastrisk bypass-prosedyren. Gallestein og urolithiasis kan være prosedyrerelaterte årsaker til smerter og kan ofte enkelt utelukkes. Ulcus i gastrojejunostomien kan gi magesmerter, men har oftest et annet symptombilde enn intern herniering og kan avklares ved gastroskopi.

Dersom akutt intern herniering foreligger, må det interveneres raskt. CT-undersøkelse kan være av hjelp i diagnostikken, men en negativ eller usikker CT-undersøkelse bør ikke føre til at en diagnostisk laparoskopi utsettes dersom symptomene gir mistanke om herniering med strangulasjon. I en studie hadde $20 \%$ av pasientene med intern herniering normale funn ved preoperativ røntgenkontrastundersøkelse av tarm eller CT (25). Generelt bør man ha lav terskel for laparoskopi eller laparotomi hos disse pasientene.

Det er viktig at pasientene selv kjenner til tilstanden og at de har fått og forstått informasjon om raskt å ta kontakt med lege ved symptomer på intern herniering. Dette gjelder særlig pasienter som blir gravide (22).

Flere av studiene som beskriver forekomst av intern herniering etter gastrisk bypass har metodologiske svakheter og er vanskelige å tolke og sammenlikne. Definisjonen av intern herniering kan være uklar, og angivelse av andelen av pasienter som blir fulgt opp, oppfølgingstid og kontrollopplegg kan mangle. Kort oppfølging og lav oppfølgingsandel kan gi et falskt inntrykk av lav forekomst av intern herniering.

Hvis man antar at forekomsten av intern herniering i dag er rundt $4-8 \%$, vil anslagsvis 100-200 av pasientene som opereres hvert år med gastrisk bypass i Norge kunne utvikle denne potensielt alvorlige komplikasjonen. Pasienter operert i utlandet kommer i tillegg. Dette tilsier at alle kirurger ved avdelinger med akutt abdominalkirurgisk beredskap bør ha kjennskap til tilstanden. Pasienter med uklare, residiverende, øvre magesmerter etter matinntak kan ha intermitterende herniering uten akutt obstruksjon eller inneklemming av tarm. Prioritert elektiv diagnostisk laparoskopi og lukning av slitser kan være aktuelt hos slike pasienter.

Det foreligger ingen generell konsensus eller godt kunnskapsgrunnlag for eventuell nytteverdi av profylaktisk lukning av mesenteriale slitser som forebygging av intern herniering etter gastrisk bypass. Enkelte retrospektive, ikke-randomiserte studier antyder redusert hyppighet av intern herniering om slitsene lukkes $(11,26)$. I Sverige pågår for tiden en randomisert studie der man tar sikte på å evaluere nytteverdien av slitslukning som profylaktisk tiltak (27).

\section{Tom Mala (f. 1968)}

er spesialist i generell kirurgi og gastroenterologisk kirurgi og arbeider som overlege ved Avdeling for gastro- og barnekirurgi og Senter for sykelig overvekt i Helse Sør-Øst, Oslo universitetssykehus.

Forfatter har fylt ut ICMJE-skjemaet og oppgir ingen interessekonflikter.

\section{Jon Kristinsson (f. 1959)}

er spesialist i generell kirurgi og i gastroenterologisk kirurgi og overlege og avdelingsleder ved Senter for sykelig overvekt i Helse Sør-Øst, Oslo universitetssykehus.

Forfatter har fylt ut ICMJE-skjemaet og oppgir ingen interessekonflikter.

\section{Litteratur}

1. Hofs $\varnothing$ D, Aasheim ET, Søvik TT et al. Oppfølging etter fedmekirurgi. Tidsskr Nor Legeforen 2011 131: 1887-92

2. Aasheim ET, Mala T, Søvik TT et al. Kirurgisk behandling av sykelig fedme. Tidsskr Nor Lægeforen 2007: 127: 38-42.

3. Larkin JO, Cooke F, Ravi N et al. Internal hernia following total gastrectomy with Roux-en-Y construction. Ann R Coll Surg Engl 2011; 93: 71-3.

4. Flørenes T. Herniering til bursa omentalis. Tidssk Nor Lægeforen 1986; 106: 836-7.

5. Comeau E, Gagner M, Inabnet WB et al. Symptom atic internal hernias after laparoscopic bariatric surgery. Surg Endosc 2005; 19: 34-9.

6. Cho M, Pinto D, Carrodeguas $L$ et al. Frequency and management of internal hernias after laparoscopic antecolic antegastric Roux-en-Y gastric bypass without division of the small bowel mesen tery or closure of mesenteric defects: review of 1400 consecutive cases. Surg Obes Relat Dis 2006 2: $87-91$

7. lannelli A, Buratti MS, Novellas S et al. Internal hernia as a complication of laparoscopic Rouxen-Y gastric bypass. Obes Surg 2007: 17: 1283-6.

8. Steele KE, Prokopowicz GP, Magnuson T et al. Laparoscopic antecolic Roux-en-Y gastric bypass with closure of internal defects leads to fewer internal hernias than the retrocolic approach. Surg Endosc 2008; 22: 2056-61.

9. Gandhi AD, Patel RA, Brolin RE. Elective laparoscopy for herald symptoms of mesenteric/internal hernia after laparoscopic Roux-en-Y gastric bypass. Surg Obes Relat Dis 2009; 5: 144-9, discussion 149. 
10. Bauman RW, Pirrello JR. Internal hernia at Petersen's space after laparoscopic Roux-en-Y gastric bypass: $6.2 \%$ incidence without closure-a single surgeon series of 1047 cases. Surg Obes Relat Dis 2009; 5: 565-70.

11. Rodríguez A, Mosti M, Sierra M et al. Small bowel obstruction after antecolic and antegastric laparoscopic Roux-en-Y gastric bypass: could the incidence be reduced? Obes Surg 2010; 20: 1380-4

12. Abasbassi M, Pottel H, Deylgat B et al. Small bowel obstruction after antecolic antegastric laparoscopic Roux-en-Y gastric bypass without division of small bowel mesentery: a singlecentre, 7-year review. Obes Surg 2011; 21: 1822-7.

13. Aghajani E, Jacobsen HJ, Nergaard BJ et al. Internal hernia after gastric bypass: a new and simplified technique for laparoscopic primary closure of the mesenteric defects. J Gastrointest Surg 2012; 16: 641-5.

14. Himpens J, Verbrugghe A, Cadière GB et al. Longterm results of laparoscopic Roux-en-Y Gastric bypass: evaluation after 9 years. Obes Surg 2012; 22: 1586-93.

15. Higa K, Ho T, Tercero F et al. Laparoscopic Rouxen-Y gastric bypass: 10-year follow-up. Surg Obes Relat Dis 2011; 7: 516-25.

16. Iannelli A, Facchiano E, Gugenheim J. Internal hernia after laparoscopic Roux-en-Y gastric bypass for morbid obesity. Obes Surg 2006; 16 : 1265-71.

17. Schneider C, Cobb W, Scott J et al. Rapid excess weight loss following laparoscopic gastric bypass leads to increased risk of internal hernia. Surg Endosc 2011; 25: 1594-8.

18. O'Rourke RW. Management strategies for internal hernia after gastric bypass. J Gastrointest Surg 2011; 15: 1049-54.

19. Quebbemann BB, Dallal RM. The orientation of the antecolic Roux limb markedly affects the incidence of internal hernias after laparoscopic gastric bypass. Obes Surg 2005; 15: 766-70, discussion 770.

20. Torres-Villalobos GM, Kellogg TA, Leslie DB et al. Small bowel obstruction and internal hernias during pregnancy after gastric bypass surgery. Obes Surg 2009; 19: 944-50.

21. Renault K, Gyrtrup HJ, Damgaard K et al. Pregnant woman with fatal complication after laparoscopic Roux-en-Y gastric bypass. Acta Obstet Gynecol Scand 2012; 91: 873-5.

22. Wax JR, Pinette MG, Cartin A. Roux-en-Y gastric bypass associated bowel obstruction complicating pregnancy - an obstreticians map to the clinical minefield. Am J Obstet Gynecol 2012; e-publisert 10.8.2012

23. Iannuccilli JD, Grand D, Murphy BL et al. Sensitiv- ity and specificity of eight CT signs in the preoperative diagnosis of internal mesenteric hernia following Roux-en-Y gastric bypass surgery. Clin Radiol 2009; 64: 373-80

24. Hope WW, Sing RF, Chen AY et al. Failure of mesenteric defect closure after Roux-en-Y gastric bypass. JSLS 2010; 14: 213-6.

25. Higa KD, Ho T, Boone KB. Internal hernias after laparoscopic Roux-en-Y gastric bypass: incidence, treatment and prevention. Obes Surg 2003; 13: $350-4$.

26. de la Cruz-Muñoz N, Cabrera JC, Cuesta M et al. Closure of mesenteric defect can lead to decrease in internal hernias after Roux-en-Y gastric bypass. Surg Obes Relat Dis 2011; 7: 176-80.

27. Clinicaltrials.gov. Internal hernia after laparoscopic gastric bypass. http://clinicaltrials.gov/ct2/ show/NCT01137201 (18.1.2013).

Mottatt 28.9. 2012, første revisjon innsendt 15.12. 2012, godkjent 18.1. 2013. Medisinsk redaktør Petter Gjersvik. 